\title{
Mitigation of groundwater iron-induced clogging by low-cost bioadsorbent in open loop geothermal heat pump systems
}

\author{
Claudia Fujita ${ }^{1} \cdot$ M. Shahbaz Akhtar ${ }^{1,2,3} \cdot$ Ray Hidaka $^{1} \cdot$ Makoto Nishigaki $^{1,2,4}$
}

Received: 19 August 2021 / Accepted: 18 January 2022 / Published online: 7 February 2022

(c) The Author(s) 2022

\begin{abstract}
Green energy production from natural resources can reduce emissions of greenhouse gases and pollutants from burning of fossil fuels in power plants. Recently, groundwater geothermal energy (GGE) is harnessed by deploying closed- and openloop heat systems. In open-loop geothermal heat pump systems (OLGHPS), groundwater is reinjected into aquifer after harnessing GGE. Nevertheless, OLGHPS face noxious clogging issue because of elusive chemistry (corrosion or precipitation) of chemical species, principally of iron ( $\mathrm{Fe})$, in pipes and aquifers during reinjection process via oxidation reactions. Plethora of filtering materials are available for removal of ions, but these are quite expensive and environmentally unsafe. More recently, low-cost, eco-friendly, green filtering materials gain much interest. These materials can remove ions from groundwater that can minimize clogging in heat exchange systems, injection wells, and aquifer. In the present study, three filtering materials, i.e., wooden charcoal (biomaterial), yamazuna fine sand, and volcanic ash, were tested to estimate their $\mathrm{Fe}$ removal capacity. In upward flow mode with minimum oxygen-water contact, serial column (each with 6 ports) experiments were conducted under constant pressure head and constant velocity conditions. Columns were connected to well water having dissolved Fe concentration of $10.85 \mathrm{mg} \mathrm{L}^{-1}$. Sampling was done at the well, column inlets, column's six sampling ports and column outlets, and samples were analyzed for Fe by atomic absorption spectroscopy. Related tested parameters include $\mathrm{pH}, \mathrm{EC}$, temperature, turbidity, porosity, particle diameter, and dissolved oxygen. Volcanic ash showed less Fe removal, while sand filter showed substantial reduction in velocity. Biomaterial (wooden charcoal) displayed higher Fe adsorption capacity compared to other materials that can be ascribed to its surface chemistry and functional groups. Under different flow rates, maximum Fe content of $3.5 \mathrm{~g} \mathrm{Fe} \mathrm{kg}^{-1}$ dry charcoal was obtained. By considering a safety factor and influence of groundwater composition, it is possible to design a biomaterial-based iron filter system to minimize Fe-induced chemical clogging in OLGHPS which is an eco-friendly, green energy source.
\end{abstract}

Keywords Dissolved iron removal $\cdot$ Chemical clogging $\cdot$ Open-loop geothermal systems $\cdot$ Retention potential $\cdot$ Wooden charcoal

M. Shahbaz Akhtar

drakhtarms@gmail.com

1 Geo-Environmental Evaluation Laboratory, Department of Environmental Design and Civil Engineering, Graduate School of Environmental and Life Science, Okayama University, Kitaku Tsushima-naka 3-1-1, Okayama 700-8530, Japan

2 Department of Sound Materials Cycle Science, Faculty of Environmental Science and Technology, Graduate School of Environmental and Life Science, Okayama University, Kitaku Tsushima-naka 3-1-1, Okayama 700-8530, Japan

3 Department of Environmental Sciences, Forman Christian College (A Chartered University), Lahore, Pakistan

4 Integration Model of Physical Properties Technology Research Association, Okayama, Japan

\section{Introduction}

Among freshwater resources (i.e., less than 3\% of total global water reserves), water confined in fractured rocks, voids, aquifers (saturated zones), and weak zoological zones/ structures (fractures and faults) is termed as groundwater. Approximately $98 \%$ of fresh liquid water is confined as groundwater, whereas remaining $2 \%$ is present in surface water bodies such as lakes, rivers, estuaries, brooks, and streams (Bouwer 2002). Water scarcity due to overexploitation demands natural or artificial recharge to augment groundwater resources. Groundwater is used for drinking, agriculture, and industrial purposes. 
Recently, groundwater is used to harness geothermal energy stored in the aquifers. This geothermal energy is emerging as an alternative, cost-effective, and eco-friendly energy source. Such renewable energy production from natural resources (solar, wind, groundwater) is an alternative approach that can mitigate air pollution and global warming by reducing greenhouse gas emissions and pollutants from burning of fossil fuels (Nazir et al. 2019; Al-Ahmed et al. 2020; Haque et al. 2020). Geohydrothermal energy can be harnessed via closed loop geothermal heat pump systems (CLGHPS) or open loop geothermal heat pump systems (OLGHPS) by exploiting annual constant temperature property of groundwater. In comparison with CLGHPS where cooling or heating is done from surrounding groundwater in the well, OLGHPS use pumped groundwater to cool down (in summer months) or to heat up (in winter months) a building, an engineered structure, a parking lot, or any other facility and then reinject it back into the aquifer. Excessive heat energy is harnessed in these systems during summer season that can be deployed for heating/warming purposes during cooler months and vice versa. Because groundwater temperature remains constant throughout the year, thus in winter season, water is warmer than air temperature and in summer season, it is cooler than the air temperature. The system comprises two wells, a so-called cooler well and a warmer well representing an extraction well and an injection well depending on summer or winter season. For example, during summer months, extraction of water is done from cold well (natively present groundwater in vicinity or injected stored water during winter months) and then via heat exchanger indirect cooling is provided (through a geothermal heat pump) and even direct cooling to the target. This process results in warming of reinjected water into well categorized as a warmer well. In aquifer, injected water is stored prior to winter months and then extracted from warm water well in winter season. Nevertheless, groundwater reinjection faces a noxious clogging issue (Rafferty 2003; Drijver and Willemsen 2001; Masciopinto et al. 2017; Parimalarenganayaki 2021). Likewise, OLGHPS face clogging issue because of precipitation of chemical species or corrosion of pipes as well as precipitation of chemical species via oxidation reactions in aquifer porous media during reinjection process.

Clogging can be divided into three categories, depending on the main influencing causes, i.e., physical, chemical, and biological clogging (Bouwer 2002; Ye et al. 2019; Jeong et al. 2018; Baveye et al. 1998). Groundwater iron is a major cause for chemical clogging. Present study was conducted to remove iron from groundwater to avoid chemical clogging. Most common methods for iron removal are based on exchange of ions (Hódi et al. 1995; Khatri et al. 2017; Olivera et al. 2018), coagulation (Simeonidis and Mitrakas 2021), microfiltration and oxidation (Ellis et al. 2000; Kalvani et al. 2021; Syed Ibrahim et al. 2018), nanobubbles-based surface techniques
(Kyzas et al. 2019; Sun et al. 2021), nanoparticles (Aragaw et al. 2021; Lim et al. 2018), ultrafiltration (Tang et al. 2021), and biobased protocols (Pacini et al. 2005; Seppánen 1992); however, these methods are not eco-friendly and cost-effective because of maintenance and operational issues. This scenario impels us to devise an eco-friendly, green, and cost-effective approach to combat clogging issue.

Carbon (mostly powdered or granular) materials are well known for their adsorption potential. Among these materials, activated carbon is an effective adsorbent. Most common functional groups on activated charcoal surfaces include carboxyl, lactone, lactol, anhydride, ether, quinone, pyrone, chromene, pyridine, quartenery and oxidized $\mathrm{N}$, pyridone, pyrrole, phenol, and carbonyl (Figueiredo and Pereira 2010). Recently, Nazir et al. (2021) have used charcoal material prepared from the leaves of Bougainvillea spectabilis to remove iron from aqueous solutions. Moreno et al. (2010) used cow-bone charcoal to test metal sorption efficiency of material from wastewater and reported better efficiency of cow bone charcoal in removing metals. Ahamad and Jawed (2011) and Sendja et al. (2021) reported possible adsorption capacity of wooden charcoal, sand, and volcanic ash for the removal of dissolved iron. Sand is conventionally used for water purification (Wotton 2002; Awan et al. 2003) as a sand filter. Similarly, volcanic ash has fine pumiceous structure (Oba et al. 1967), rich in mineral contents, and has higher surface area (Sendja et al. 2021). Volcanic ash is used to remove metals from aqueous solutions (Toscano et al. 2008; Esmaeili et al. 2019). Ahmad and Jawed (2010) used wooden charcoal and conducted column and batch tests in downward flow mode and reported that adsorption capacity relies on flow rates, temperature, and depth of bed. Nevertheless, these tests were conducted in a mode flowing downward, on a small-scale, and the influence of contact of oxygen with contaminated water was not considered.

Generally, anaerobic conditions are predominant in an aquifer. Therefore, in groundwater, iron $(\mathrm{Fe})$ exists in soluble form, i.e., ferrous iron $\left(\mathrm{Fe}^{2+}\right)$. During extraction of groundwater to the surface, contact between $\mathrm{Fe}$ and oxygen primarily results in the formation of insoluble ferric state $\left(\mathrm{Fe}^{3+}\right)(\mathrm{Eq} .1)$ and secondary to $\mathrm{Fe}(\mathrm{III})$-hydroxide $\left(\mathrm{Fe}(\mathrm{OH})_{3}\right.$ forms (Eq. 2). The reactions are influenced by environmental factors such as temperature, $\mathrm{pH}$, and oxygen content. For instance, a minimal total of oxygen of $0.15 \mathrm{mg} \mathrm{O}_{2} / \mathrm{mg} \mathrm{Fe}^{2+}$ is needed for the oxidation of ferrous into ferric state (Mutschmann and Stimmelmayr 1991). Resultant redox reaction is shown in Eq. 3 (Teunissen 2007).

$4 \mathrm{Fe}^{2+}+\mathrm{O}_{2}+2 \mathrm{H}_{2} \mathrm{O} \leftrightarrow 4 \mathrm{Fe}^{3+}+4 \mathrm{OH}^{-}$

$4 \mathrm{Fe}^{3+}+4 \mathrm{OH}^{-}+8 \mathrm{H}_{2} \mathrm{O} \leftrightarrow \mathrm{Fe}(\mathrm{OH})_{3}+8 \mathrm{H}^{+}$

$4 \mathrm{Fe}^{2+}+\mathrm{O}_{2}+10 \mathrm{H}_{2} \mathrm{O} \leftrightarrow 4 \mathrm{Fe}(\mathrm{OH})_{3}+8 \mathrm{H}^{+}$ 
Stable $\mathrm{Fe}^{3+}$ (hydro)oxides (e.g., goethite) with crystalline structures are produced after iron intermediate products with partial oxidation and less crystalline nature. In addition, during well case corrosion, reduced products such as $\mathrm{Fe}_{3} \mathrm{O}_{4}$ (magnetite), $\mathrm{FeS}$ (troilite), and $\mathrm{FeS}_{2}$ (marcasite) can also be formed (Hoon et al. 2017). Solubility of Fe(III) hydroxide in water is less and it starts to precipitate even at lower concentrations. The resultant precipitates are commonly termed as 'rust.' The major cause of chemical clogging problems is precipitated flakes (Akhtar et al. 2021). During groundwater extraction, water reacted with oxygen. Resultant corrosion or precipitation in pipes can drastically lower heat conductivity and efficiency of the system. During reinjection of water into aquifer, resultant flakes might plug the voids and can decrease permeability that can ultimately result in clogging. Iron present in groundwater must be removed without oxygenation of groundwater to avoid clogging during water injection process. Generally, most methods in practice rely on oxygenation of groundwater followed by precipitation. However, these methods have limited efficiency and applicability.

Keeping in view the above scenario, there is a dire need to explore cost-efficient and environmental friendly strategy/method/material to combat iron-induced noxious clogging for smooth functioning of OLGHPS, particularly for its application in resource-limited countries. Recently, low-cost, eco-friendly, green materials gain much interest. These materials might have the potential to remove iron from groundwater that can minimize iron-induced clogging. The objective of the present study is to investigate the iron removal capacity from groundwater used in OLGHPS by three low-cost, eco-friendly and easily available materials in Japan, i.e., biomaterial (wooden charcoal), yamazuna fine sand, and volcanic ash. Three filtering materials were filled in columns connected with groundwater in present study. Column experiments under constant pressure head and constant velocity conditions with upward flow mode were conducted, and the contact between oxygen and groundwater was avoided by purging nitrogen $\left(\mathrm{N}_{2}\right)$ gas in experimental protocol.

\section{Materials and methods}

\section{Experimental site and experimental setup}

Present experiments were conducted at Okayama University, Okayama prefecture, Chūgoku region, Japan $\left(34.6871^{\circ} \mathrm{N}\right.$, $\left.133.9222^{\circ} \mathrm{E}\right)$. Vertically oriented columns having dimensions (height $(\mathrm{h})=30 \mathrm{~cm}$ and diameter $(\mathrm{d})=10 \mathrm{~cm}$ ) were used in present experiments. Different steps of experimental setup are represented in Fig. 1. The columns were prepared with 6 evenly spaced (each $5 \mathrm{~cm}$ apart) sampling ports to measure the iron content of the water from different points along the flow path. At each sampling port of column as outlined in Fig. 1, breakthrough curves of dissolved Fe concentration were estimated. Groundwater extracted by well pump was directly introduced into water supply tank via tube (enclosed) with constant head. Physicochemical properties of used groundwater were (i) average temperature $\left(18^{\circ} \mathrm{C}\right)$, (ii) ferrous ions $(10.85 \mathrm{mg} / \mathrm{L})$, (iii) $\mathrm{pH}(6.61)$, (iv) electric conductivity (EC) $(42.95 \mathrm{mS} / \mathrm{m})$, dissolved oxygen

Fig. 1 Experimental setup

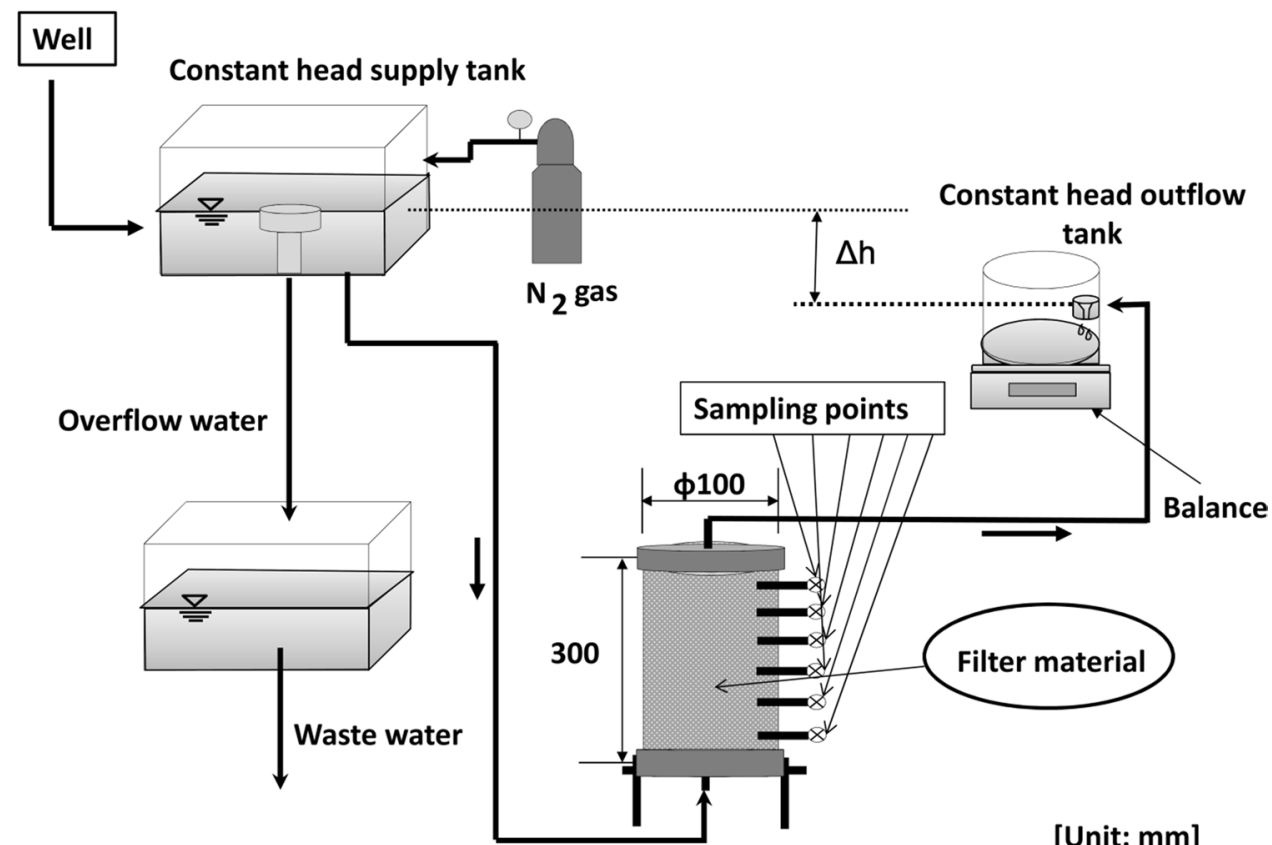


(DO) $(0.5 \mathrm{mg} / \mathrm{L})$, and redox potential (Eh) $(-47 \mathrm{mV})$. The supply and outflow tanks with constant head ensured the controlled flow during experiments. To minimize oxygen intrusion, sealing of water supply tank was ensured. Furthermore, constant head supply tank was induced with $\mathrm{N}_{2}$ gas purging to displace $\mathrm{O}_{2}$ in the tank. To ensure the zero pressure in supply tank, drainage water from constant head supply tank was regulated by connecting with another tank (second drainage tank). Columns bottoms were connected to supply tank via tubes, and column outflow (each outflow) was connected to outflow tank with constant head.

\section{Filtering materials and sample analysis}

Oven-dried charcoal materials (free from impurities such as leaves, stones, debris) were used to fill the columns. Tested wooden charcoal was prepared by 'JFE Recycling Management Japan, Inc. Kurashiki $\left(34.5850^{\circ} \mathrm{N}\right.$, $133.7720^{\circ} \mathrm{E}$ ), Japan.' The wooden waste was crushed into a size of below $30 \mathrm{~mm}$. Resultant small particles were carbonized at high temperatures $\left(>8000^{\circ} \mathrm{C}\right)$ in an oscillating carbonization furnace. Then, the material was cooled by a cooling conveyer, and by a wind force sorter non-burnable substances were removed. The final product had an ash content of $9.8 \%$, volatile matter content of $3.4 \%$, and a fixed carbon content of $86.8 \%$ (values are on dry matter basis). A detailed 25 times enlarged microscopic picture of the used charcoal material is shown in Fig. 2. Fine sand (yamazuna), collected from Chiba prefecture $\left(35.3354^{\circ} \mathrm{N}\right.$, $\left.140.1833^{\circ} \mathrm{E}\right)$, Japan, and a fine-grained white pumiceous volcanic ash (Shirasu), collected form Kyushu (33.5663 ${ }^{\circ}$ $\left.\mathrm{N}, 130.7159^{\circ} \mathrm{E}\right)$ southwestern Japan, were also filled in separate columns. Yamasuna is a fine sand mined in Chiba prefecture, Japan, for several construction uses (Igarashi and Saito 2005) and has higher specific gravity, more

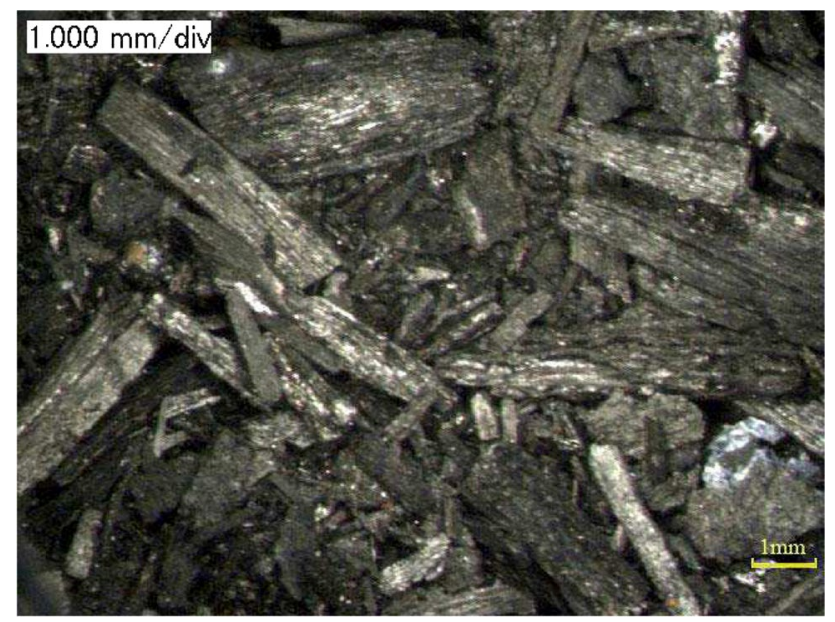

Fig. 2 Microscopic (25 times enlarged) view of wooden charcoal heterogeneity, and maximum dry density than silica sand (Zhou et al. 2014). These materials were tested along with bioadsorbent (charcoal) in the present study as their effectiveness was reported earlier in iron removal studies where adsorption mechanism was attributed to ion exchange or chemisorption processes (Sendaja et al. 2021; KwakyeAwuah et al. 2019; Ando et al. 2017; Vries et al. 2017).

Particle diameter was determined by Horizontal Turn Sieve Shaker SKH-01(AS ONE Corporation). The sieving analysis was conducted by using sieves of sizes ranging from $0.063 \mathrm{~mm}, 0.0075 \mathrm{~mm}, 0.106 \mathrm{~mm}, 0.25 \mathrm{~mm}$, $0.85 \mathrm{~mm}, 2 \mathrm{~mm}, 4.75 \mathrm{~mm}$, and $9 \mathrm{~mm}$. Each sieve was weighed before use, and then the sieves were set up on the instrument. An amount of $500 \mathrm{~g}$ was put on the top sieve, and then the instrument was switched on and shake the soil for $10 \mathrm{~min}$. Then, each sieve was weighted again and the particle diameter passing each sieve was obtained. To minimize transport of impurities and very fine particles into aquifer, filter materials were washed based on previous washing experiments for different velocities. Water flows into a column under gravity with constant head tank. At different time intervals $(5,15,30,60,120,240$, and $480 \mathrm{~s}$ ), samples were collected into $10-\mathrm{mL}$ glass vials from column outlets. Turbidity analysis was done with calibrated turbidimeter (P2100 from HACH) after shaking. End products of carbonization process in charcoal such as BTEX (benzene, toluene, ethylbenzene, and xylene) and PAH (polycyclic aromatic hydrocarbons) were estimated by chromatography during washing experiment.

During column studies, sampling was done at the well, column inlets, column's six sampling ports, and column outlets. Atomic absorption spectroscopy (AAS) technique was used to quantify the dissolved iron in liquid samples with a flame atomic absorption spectrometer (Z-6100 polarized Zeeman, Hitachi) after calibrating the instrument with solutions of known iron concentrations. Adsorbed iron amount on adsorbent material surfaces (every $5-\mathrm{cm}$ layer) of each column is estimated by AAS technique after extracting the iron from adsorbent with extractants (Ryan et al. 2001). Fe concentration in blank charcoal material was also determined by AAS technique. Electrical conductivity (EC) was determined with EC meter (Horiba Ltd. Japan, Conductivity Meter B-173 Twin Cond.) after calibrating the instrument with reagent grade $0.01 \mathrm{M} \mathrm{KCl}$ solution. $\mathrm{pH}$ was determined by potentiometry technique by using $\mathrm{pH}$ meter (WM-32EP) after calibrating the instruments with standard solution $(\mathrm{pH}=4.01$ and $\mathrm{pH}=6.86$ ). Temperature and DO (dissolved oxygen) were estimated by using 17SD pH/ORP, DO, CD/TDS, Salt Meter of Sato Shouji Inc., Japan. One point calibration of DO was done with air. DO meter was equipped with temperature sensitive probe that automatically adjust DO with sample temperature. 


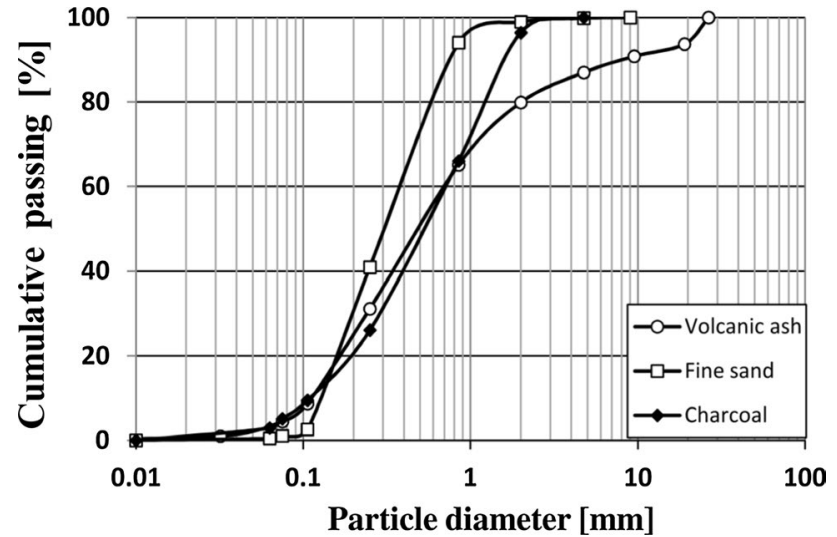

Fig. 3 Distribution curves for particle sizes of three filtering materials, i.e., wooden charcoal, volcanic ash, and fine sand. Cumulative passing: cumulative weight percent passed through the sieve (the fraction that is finer than each subsequent grain size)

\section{Experiments with constant pressure head}

Initial studies were conducted under constant pressure head $(\Delta \mathrm{h})$, where $\mathrm{h}$ is denoted as hydraulic head. In constant pressure head experiments, three different materials [wooden charcoal (0), fine sand (0), and volcanic ash (0)] were used to estimate their relative filtering capacity for iron removal in pumped groundwater. The distribution curves of particle sizes for all three materials are shown in Fig. 3, and the determined physical characteristics are represented in Table 1. Tested charcoal has average particle diameter ranging from 0.03 to $5 \mathrm{~mm}$. Particle diameter of about $20 \%$ mass fraction of volcanic ash ranges from 2 to $30 \mathrm{~mm}$. About
$10 \%$ mass fraction of charcoal has particle diameter less than $0.1 \mathrm{~mm}$, whereas sand does not show fine particles below $0.1 \mathrm{~mm}$.

\section{Constant velocity experiments}

In a second series, constant velocity condition (changing pressure head) experiments were conducted. In these experiments, two filtering materials, i.e., charcoal [charcoal (A), charcoal (B), charcoal (C) - each with different constant velocity] and fine sand [fine sand (A), fine sand (B], were tested for Fe removal capacity. Volcanic ash displayed less applicability because of low filtering capacity in constant pressure head experiments; therefore, it was not further considered in constant velocity experiments. The velocity was kept almost constant throughout the experiments by changing the pressure head. Experiments were stopped on detection of Fe concentration in outflow tank, and $2-3 \mathrm{~cm}$ layers of filtering materials were retrieved and sampled to estimate total $\mathrm{Fe}$ contents. The velocities were determined based on porosity of the prepared columns and differential times for retaining Fe-contaminated groundwater in filtering medium. Physical properties of experimental materials are represented in Table 2.

\section{Results and discussion}

To ensure that no turbid water should be injected into aquifer in OLGHPS, washing experiment was conducted. Filtering material was washed with tap water (turbidity $=0.18 \mathrm{NTU}$ ) for different velocities in column $(30 \mathrm{~cm}$ height and $10 \mathrm{~cm}$
Table 1 Materials characteristics used in constant pressure head experiments

\begin{tabular}{lllll}
\hline & Unit & Volcanic ash (0) & Fine sand (0) & Charcoal (0) \\
\hline Permeability & {$[\mathrm{cm} / \mathrm{s}]$} & $1.0 \mathrm{E}-1$ & $4.7 \mathrm{E}-2$ & $4.9 \mathrm{E}-2$ \\
$\mathrm{D}_{10}$ & {$[\mathrm{~mm}]$} & 0.11 & 0.14 & 0.12 \\
$\mathrm{D}_{60}$ & {$[\mathrm{~mm}]$} & 0.38 & 0.70 & 0.70 \\
Porosity & {$[-]$} & 0.67 & 0.39 & 0.90 \\
Specific gravity & {$\left[\mathrm{g} / \mathrm{cm}^{3}\right]$} & 2.29 & 2.74 & 1.45 \\
Specific surface area & {$\left[\mathrm{m}^{2} / \mathrm{g}\right]$} & - & - & $139-154$ \\
\hline
\end{tabular}

$\mathrm{D}_{10}$ and $\mathrm{D}_{60}$ : diameter where $10 \%$ and $60 \%$ of particles are finer than this size, respectively

Table 2 Characteristics of experimental materials under constant velocity

\begin{tabular}{|c|c|c|c|c|c|c|}
\hline & & Fine sand (A) & Fine sand (B) & Charcoal (A) & Charcoal (B) & Charcoal (C) \\
\hline Velocity (V) & {$[\mathrm{cm} / \mathrm{s}]$} & $1.8 \mathrm{E}-2( \pm 7 \%)$ & $1.6 \mathrm{E}-2( \pm 20 \%)$ & $1.7 \mathrm{E}-2( \pm 9.8 \%)$ & $8.4 \mathrm{E}-3( \pm 10 \%)$ & $4.2 \mathrm{E}-3( \pm 10 \%)$ \\
\hline Retention time $\left(t_{r}\right)$ & {$[\mathrm{min}]$} & 15.0 & 15.0 & 15.0 & 30.0 & 45.0 \\
\hline Porosity & {$[-]$} & 0.38 & 0.40 & 0.61 & 0.59 & 0.85 \\
\hline Dry biomass & {$[\mathrm{g}]$} & 3586.7 & 4293.8 & 813.9 & 532.1 & 766.6 \\
\hline
\end{tabular}

Letters A-C along with charcoal filtering material indicate different velocities in experiments under constant velocity conditions 
diameter) experiment. Turbidity test was conducted because it is a good indicator for water quality. Turbidity is a measure of the degree (measured in NTU: Nephelometric Turbidity Units) to which the water loses its transparency due to the presence of suspended particles (SP). There is a direct relationship between turbidity and SP. Also, heavy metals, pesticides, and toxic organic compounds can attach to SP. Although critical value of $5 \mathrm{NTU}$ is recommended for drinking water by WHO, 1 NTU is considered an ideal value. Critical value of 5 NTU was ensured for filtering materials. For example, a critical value of 1 NTU was reached in charcoal after one complete pass of about $2.5-\mathrm{L}$ water. In addition, end products of carbonization process in charcoal such as BTEX (benzene, toluene, ethylbenzene, and xylene), PAH (polycyclic aromatic hydrocarbons) and other harmful substances were not detected during washing experiment. These results suggested that there will be no issue in terms of water quality by using charcoal as a filtering material.

\section{Constant pressure head Experiments}

In constant pressure head experiments, system conditions such as oxygen levels in the well outlet and in the face of column inlet, ambient temperature, electrical conductivity (EC), and flow rate were observed throughout experiments. All measured parameters are shown in Table 3. The oxygen level at well outlet was approximately around $0.5 \mathrm{ppm}$ and remained constant. The room temperature showed a slight increase due to rising air temperature. The negligible changes or fluctuations in EC values were observed from column inlets to outlets. They occurred due to reactions and adsorption process in the filter medium. According to the $\mathrm{pH}$ measurements, a slight increase was observed in overall experiments. $\mathrm{pH}$ is an important parameter in sorption/ adsorption processes.

Substantial changes in the adsorption equilibrium may occur due to changes in $\mathrm{pH}$ (Garcia-Araya et al. 2003; Stumm and Morgan 1996; Worch 2012). The main effects relying on $\mathrm{pH}$ are the protonation/ deprotonation of the groundwater and the surface charge diversity of the adsorbent. Acidic or alkaline species can change/modify the

Table 3 Measured parametric values in experiments with constant pressure head

\begin{tabular}{ll}
\hline Oxygen $[\mathrm{ppm}]($ at the well) & 0.5 \\
\hline $\mathrm{pH}[-]$ (charcoal filter columns) & $\begin{array}{l}\text { Column inlet: } 6.74( \pm 0.04) \\
\text { Column outflow: } 6.95( \pm 0.09)\end{array}$ \\
Electric conductivity $(\mathrm{EC})[\mathrm{mS} / \mathrm{cm}]$ & Column inlet: $0.44( \pm 0.01)$ \\
(charcoal filter columns) & Column outlet: $0.45( \pm 0.03)$ \\
Room temperature $\left[{ }^{\circ} \mathrm{C}\right]$ (laboratory) & $23.7( \pm 1.8)$ \\
& Max: $26.7 ;$ Min: 20.3 \\
\hline
\end{tabular}

surface chemistry due to reactions with surface groups of adsorbents (Mohamed 2011; Stumm and Morgan 1996). pHdependent functional groups of the adsorbent show interactions with water that results in transformation of surface sites into active sites (Contescu et al. 1998; Radovic, 1999; Stumm and Morgan 1996). Carbonaceous adsorbents like charcoal have functional groups on their surfaces that can result in their protonation or deprotonation processes. Functional groups such as carboxyl, lactone, lactol, anhydride, ether, quinone, pyrone, chromene, pyridine, quartenery and oxidized $\mathrm{N}$, pyridone, pyrrole, phenol, and carbonyl are present on surfaces of on activated charcoal (Figueiredo and Pereira 2010). When $\mathrm{pH}$ is low, adsorbent surfaces are positively charged, and when $\mathrm{pH}$ is high, surfaces are negatively charged (Stumm and Morgan 1996; Worch 2012). When $\mathrm{pH}<\mathrm{pKa}$ (-ve log of acid dissociation constant), mainly protonated form is prevalent, and when $\mathrm{pH}>\mathrm{pKa}$, deprotonated form is common (Mohamed 2011; Stumm and Morgan 1996). These effects can cause $\mathrm{pH}$-dependent evidential variations in the adsorption equilibrium (László et al. 2007; Stumm and Morgan 1996).

The flow rates were decreasing with operation time in all experiments conducted under constant pressure head as shown in Fig. 4. Until the dashed line A in Fig. 4, initial unstable pressure heads were observed which might be ascribed to entrapped air remained in the micro pores. After the line A, the velocity in the column slightly decreased over time due to clogging of the inlet by iron precipitates. After the dashed line B in Fig. 4, an increase in the flow rate due to back flushing was followed by a decrease in flow rate due to clogging.

On the onset of breakthrough of dissolved Fe concentration at the outlet tank, experimental tests were stopped. Among all filter experiments, fastest breakthrough (around 13 days) was observed in volcanic ash material; hence, this material displayed less filtering ability and omitted in further experiments. Remaining filtering materials (charcoal (0) and fine sand (0)) were selected for further studies because of their better adsorption potential for Fe. During the experiments, samples of the water were taken at 6 ports from different heights of the column and analyzed. The breakthrough curves of the three columns are depicted in Fig. 5 for two sampling times, i.e., one at the beginning and one at the termination of experiments. The breakthrough curve showed the time-dependent relationship between the adsorbate initial $\mathrm{Fe}$ concentration (column inlet) and adsorbate Fe concentration at outlet (column outlet). Breakthrough curves are plotted in Fig. 5 according to different filtered volumes. Breakthrough curve of $\mathrm{Fe}$ in fine sand (0) column was observed after 66 days, whereas the breakthrough of $\mathrm{Fe}$ in the charcoal (0) column was observed after 35 days. Nevertheless, 2.75 times more water $(2471.67 \mathrm{~L})$ was filtered in charcoal (0) column compared to fine sand (0) (867.9 L) column. 
Fig. 4 Velocity changes under constant pressure head experiments

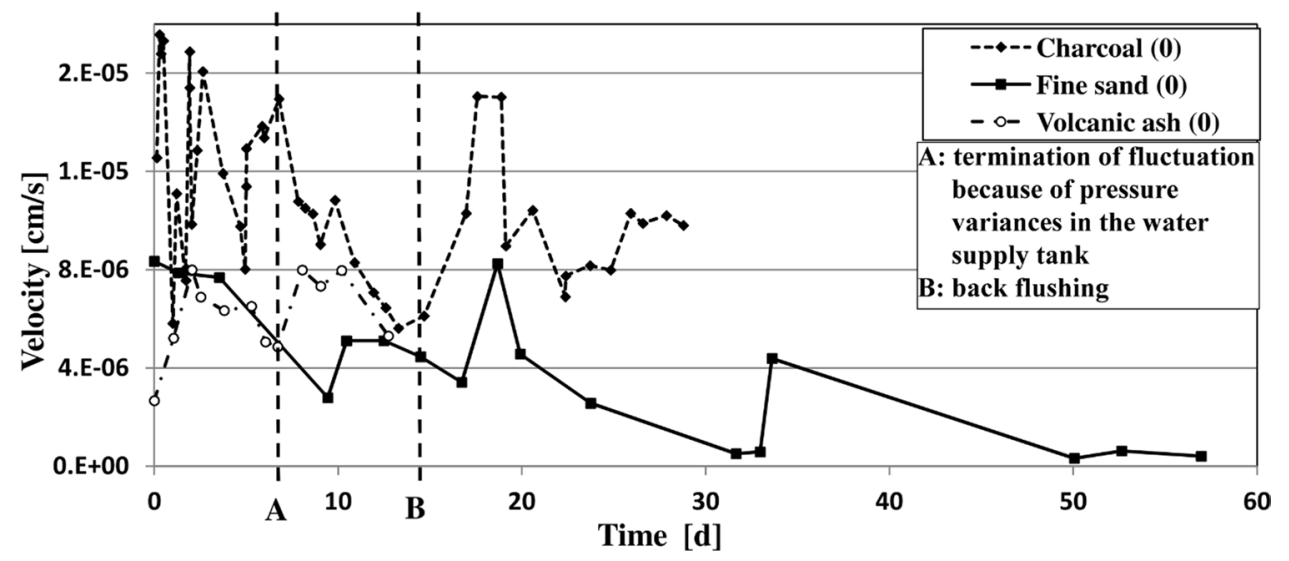

Fig. 5 Breakthrough curves of filtering materials [(charcoal $(0)$, fine sand (0), and volcanic ash (0)] used in columns with constant pressure head, plotted by considering different filtered water volumes for two sampling times. The number ' 0 ' along with filtering materials is used for the constant head pressure experiments. $\mathrm{C}_{0}$ is adsorbate $\mathrm{Fe}$ concentration at column inlet and $\mathrm{C}$ is adsorbate Fe concentration at column port/outlet

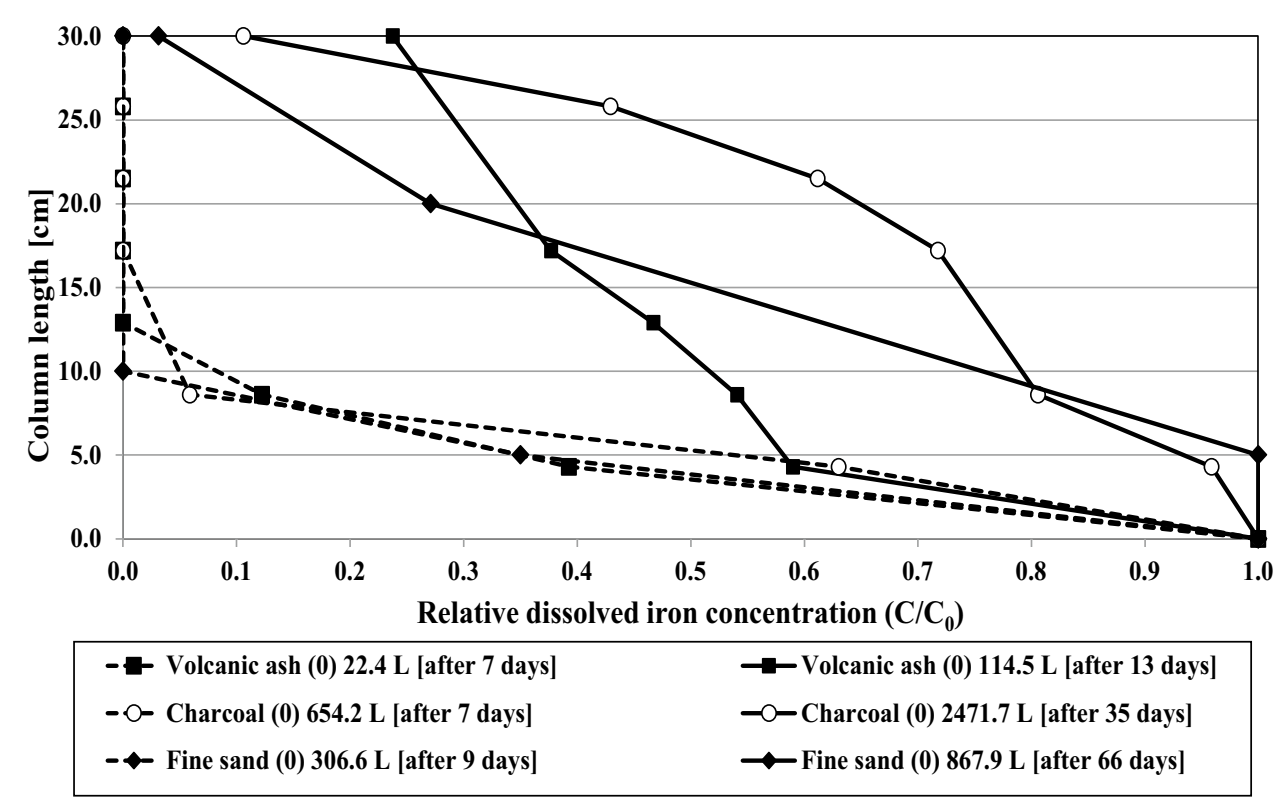

\section{Experiments under constant velocity}

By considering porosity of the filter medium and contact times with groundwater (residence time of 15, 30 and $45 \mathrm{~min}$ ), experiments with constant velocity were conducted. Different parameters (permeability of filter materials, outflowing rate, and velocity) were observed during the experiments. The changes in velocity with respect to operational experimental time are represented in Fig. 6. It was observed that within first two days of operation, permeability curve was decreased for each column. Nonetheless, blockage occurs in inlet connection of the columns by Fe precipitates that is unavoidable due to pumping. To remove these $\mathrm{Fe}$ precipitates, periodic back flushing was done in the columns, which is followed by an increase in permeability that is represented in Fig. $6 b$ in the form of vertical dotted lines with the capital letter 'B'.
Fluctuations at the beginning of the experiments were observed due to entrapped air in the filtering medium that could be visually observed in the tubes as well. Fine sand proved to be not suitable filtering material based on obtained results. Blockage occurred in column of fine sand as it was evidenced by decrease in velocity. Camprovin et al (2017) also reported clogging in sand filtered surface water systems. Even when the Fe precipitates were removed from the inlet by deploying back flushing technique, still the velocity did not show any increase. This can be ascribed to the movement of finer particles that can result in the blockage of flow paths and ultimately the velocity was decreased with time. To testify the impact of suspended matter on this clogging mechanism, washed sand material (fine sand (B) with $0.2 \mathrm{~mm}$ sieve opening) was filled in second column. Nevertheless, even a rapid decrease in velocity was also observed in washed sand filter column without no chance of recovery. This clogging issue is recognized as physical clogging 
Fig. 6 a Changes in velocity in entire operational/experimental time. b Velocity changes plotted for first 3 days, and their recovery by changes in pressure head and flushing back. Letters A-C along with charcoal filtering material indicate different velocities in experiments under constant velocity conditions

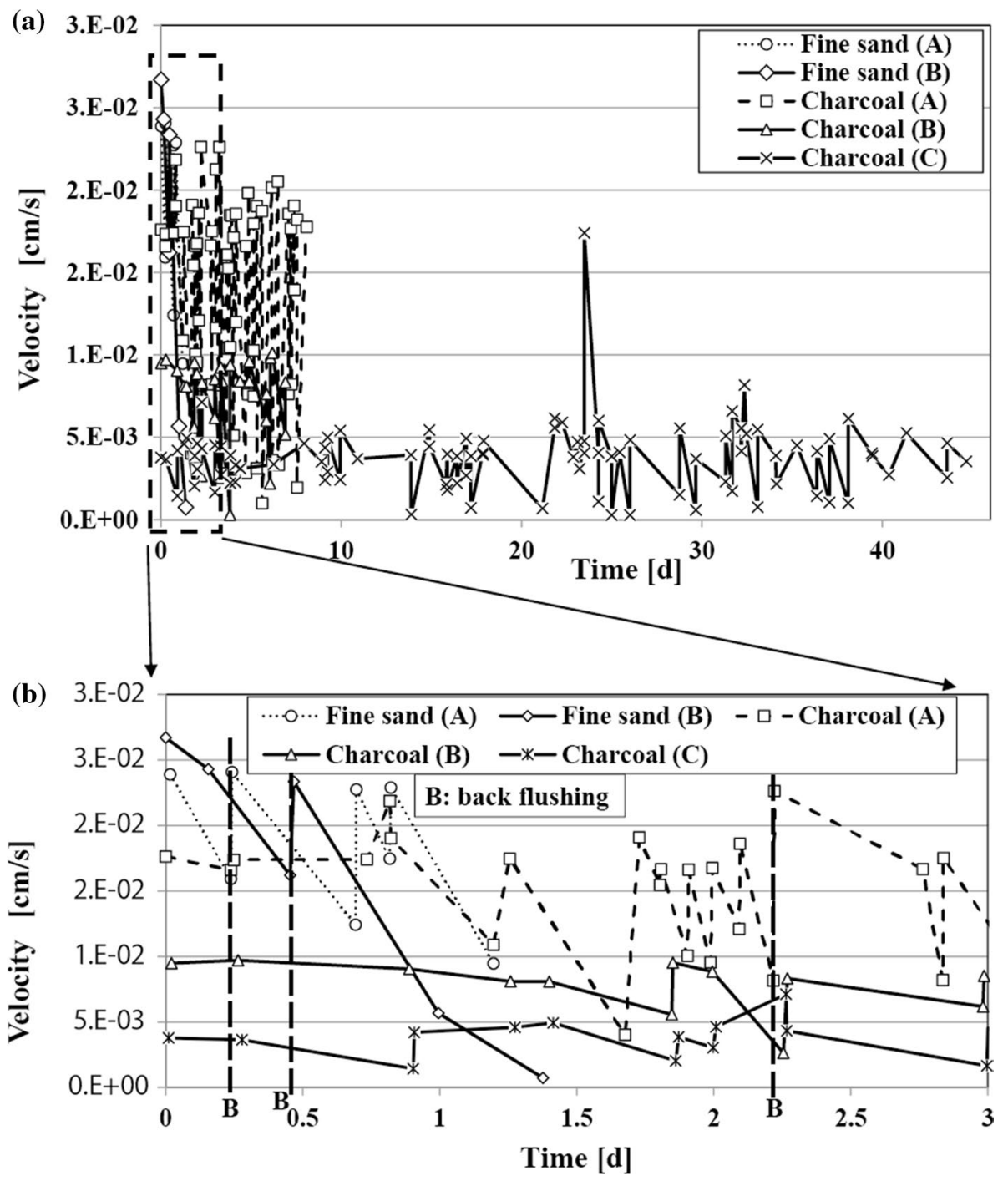

phenomenon (Ruemenapp et al. 2013; Shen and Ni 2017; Zhao et al. 2021; Zheng et al. 2020; Akhtar et al. 2021); hence, it is plausible to conclude that sand is not a viable filtering material for Fe removal from groundwater particularly for higher volumes of water or for commercial scale.

The breakthrough curves representing relatively dissolved Fe concentrations in columns are depicted in Fig. 7. The breakthrough curves were plotted by considering different filtered water volumes for two sampling times, i.e., one a few days after the start of experiment, and the second one at the end of the experiments when Fe concentration was observed in the outlet tank. When the breakthrough of iron concentration was obtained, charcoal (A) column filtered $891 \mathrm{~L}$ of groundwater contaminated with iron, whereas charcoal (B) and charcoal (C) columns filtered 541 L and $1007 \mathrm{~L}$ of groundwater, respectively.

2-3 cm layers of filtering materials were separated to estimate Fe amount retained in charcoal followed by an oven drying for $24 \mathrm{~h}$ prior to analysis of total iron retained in each layer. Iron precipitation in first $5 \mathrm{~cm}$ of the columns resulted in substantially higher contents of retained Fe. Hence, during calculation of Fe retention capacity, these values were neglected. In addition, the blank average value of total Fe concentration of charcoal material was found to be approximately $1.1 \mathrm{~g} \mathrm{Fe}$ per kg dry biomass of charcoal. The average total Fe contents measured at 15-20 cm column height of charcoal (0) column study (conducted under constant pressure head conditions) was $2.3 \mathrm{~g} \mathrm{Fe}$ per kg dry mass of charcoal. Hence, this column under its experimental conditions retained $1.2 \mathrm{~g}$ Fe per $\mathrm{kg}$ dry mass of charcoal that was lower when compared to the values obtained in other experiments. The columns used in experiments with constant velocity conditions displayed different results. In the charcoal (A) column, where Fecontaminated water was retained about $15 \mathrm{~min}$, total $\mathrm{Fe}$ content observed at basal column height $\left(2 / 3^{\text {rd }}\right)$ was $4.6 \mathrm{~g}$ $\mathrm{Fe} \mathrm{kg}^{-1}$ dry biomass of charcoal. This indicates Fe retention capacity of $3.5 \mathrm{~g} \mathrm{Fe} \mathrm{kg}^{-1}$ dry biomass of charcoal 
Fig. 7 Breakthrough curves of relative dissolved Fe concentration of the water samples for charcoal (a), charcoal (b) and charcoal (c), showing two sampling times. Letters A-C along with charcoal filtering material indicate different velocities in experiments under constant velocity conditions. $\mathrm{C}_{0}$ is adsorbate $\mathrm{Fe}$ concentration at column inlet, and $\mathrm{C}$ is adsorbate Fe concentration at column port/outlet

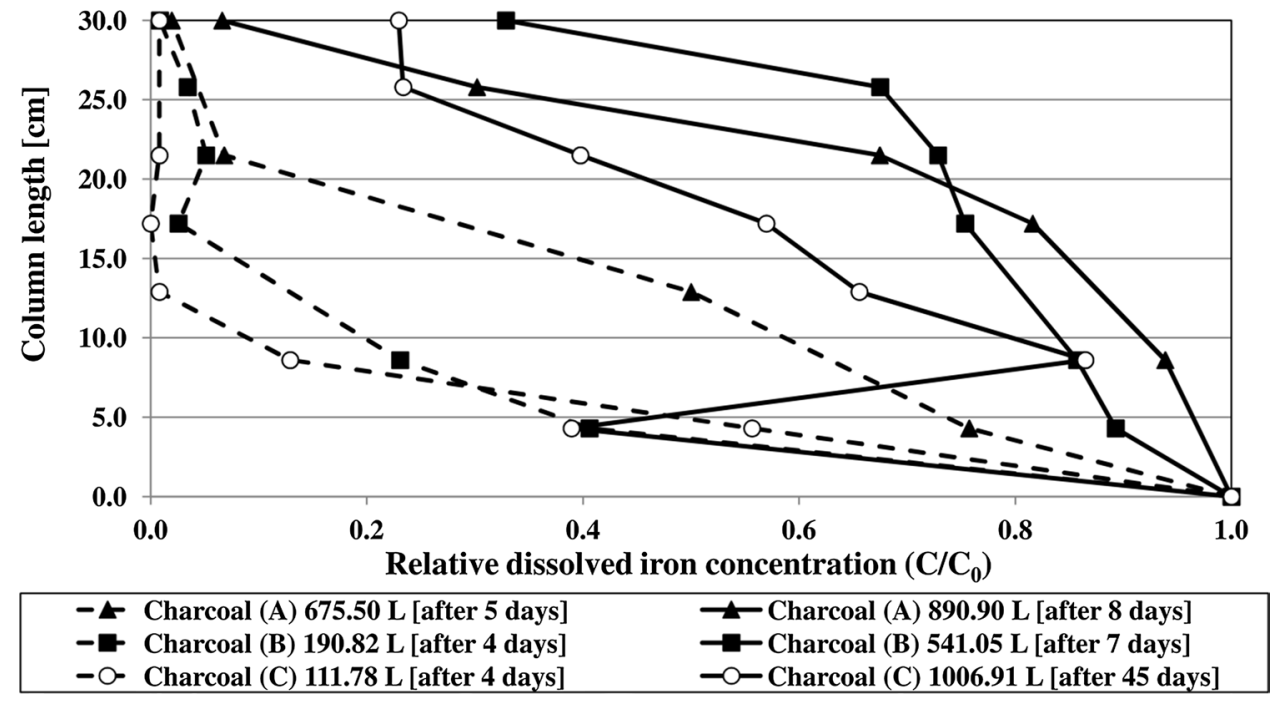

by considering blank average Fe content of charcoal. The charcoal (B) and (C) columns also retained $3.5 \mathrm{~g} \mathrm{Fe} \mathrm{kg}^{-1}$ dry biomass of charcoal. Substantial retention of iron by carbon-based biomaterial is due to its better sorption characteristics because of unique surface chemistry and functional groups (Figueiredo and Pereira 2010; Ahmad and Jawad 2010; Haque et al. 2020; Lim et al. 2018).

A summary of mass balance calculations is shown in Table 4 . The mass balance was considered only for the experiments under constant velocity conditions. From the mass balance calculation, it is recognized that the calculation was not balanced. The reason of this might be that the determination of the real actual velocity in former experiments was too high. As the velocity decreased during measurement intervals, actual constant velocity cannot be assumed. Furthermore, it was difficult to keep the system under anaerobic conditions that resulted in the intrusion of precipitated iron into the columns. This phenomenon caused the velocity reductions. Therefore, back flushing was done frequently to overcome this phenomenon and precipitated as well as adsorbed iron may have been washed out due to back flushing. However, under such high iron concentrations and under natural conditions, the filter also needs to be back flushed frequently in the field practice. Thus, the determined adsorption capacity may be higher as well as the filtered water volume may be lower in the real case.

Experimental data showed that wooden charcoal can be suitable filtering material that can be deployed effectively to remove iron from groundwater. Among three tested materials (volcanic ash, yamazuna fine sand, and charcoal), substantial Fe retention capacity was observed in charcoal material. These results are in consonance of earlier results reported on charcoal as an efficient adsorbent for metals and metalloids (Siabi et al. 2021; Deliyanni et al. 2015; Annaduzzaman et al. 2021; Da'ana et al. 2021). Thus, charcoalbased biomaterials can be deployed as an efficient adsorbent due to their different functional groups and large surface area for sorption processes. Least retention capacity was observed in the case of volcanic ash. Nevertheless, retention capacities were also observed in the case of fine sand filtering material, but fine sand material was easily blocked and showed more reduction in velocity. Therefore, fine sand material might be suggested in those types of filters where slow velocity is required during operation. Experiments conducted with charcoal filter materials with different velocities or otherwise with different retention times of groundwater contaminated with $\mathrm{Fe}$ indicated that when higher filtered water volume and short time duration are considered, charcoal (A) (retention

Table 4 Mass balance of constant velocity experiments

\begin{tabular}{|c|c|c|c|}
\hline & Charcoal (A) & Charcoal (B) & Charcoal (C) \\
\hline Dry biomass $[\mathrm{g}]$ & 813.9 & 532.1 & 766.6 \\
\hline Water volume (filtered) [L] & 890.9 & 541.05 & 1006.9 \\
\hline Adsorbed iron amount on charcoal $[\mathrm{g}]$ (calculated based on $3.5 \mathrm{~g} \mathrm{Fe} / \mathrm{kg}$ dry biomass of charcoal) & 2.85 & 1.86 & 2.68 \\
\hline $\begin{array}{l}\text { Removed amount of iron }[\mathrm{g}] \text { (calculated based on filtered water volume (filtered) and initial } \\
\text { concentration of } 10.85 \mathrm{mg} / \mathrm{L} \text { ) }\end{array}$ & 9.66 & 5.87 & 10.92 \\
\hline
\end{tabular}

Letters A-C along with charcoal filtering material indicate different velocities in experiments under constant velocity conditions 
time $\left(\mathrm{t}_{\mathrm{r}}\right)=15 \mathrm{~min}$ and velocity $\left.(\mathrm{V})=0.08 \mathrm{~L} \mathrm{~min}^{-1}\right)$ displayed better potential for filtered water $(891 \mathrm{~L})$ during eight days. However, for longer life span and use, constructed filter demands more filtered water volume. The charcoal (B) column $\left(t_{r}=30 \mathrm{~min}\right)$ filtered less amount of water $(541-\mathrm{L})$ during seven days that is approximately $60 \%$ of water volume that is filtered by charcoal (A) column. Nonetheless, charcoal $(C)$ column $\left(t_{r}=45 \mathrm{~min}\right.$ and $\left.V=0.02 \mathrm{~L} \mathrm{~min}^{-1}\right)$ filtered the highest Fe-contaminated groundwater; however, 45 days were required for filtration because of its low velocity.

Iron retention capacity of charcoal (A), (B) and (C) columns is same, i.e., $3.5 \mathrm{~g} \mathrm{Fe} \mathrm{kg}^{-1}$ dry biomass of charcoal. The experimental results negate the strong dependence of retention capacity on retention time or rather contaminated water velocity. However, when filtered water volumes are considered, $60 \%$ filtration was achieved in charcoal (B) column when compared with charcoal (A) column irrespective of lesser retention time in the former column. Therefore, $\mathrm{V}=0.04 \mathrm{~L} \mathrm{~min}^{-1}$ or rather a $\mathrm{t}_{\mathrm{r}}=30 \mathrm{~min}$ might not be considered optimum for application of effective filtration. Nevertheless, a constant flow rate and other environmental factors (e.g., $\mathrm{pH}$, temperature, and native $\mathrm{Fe}$ concentration in groundwater) that can influence the retention capacity should be considered for practical purposes (Worch 2012).

Furthermore, in another field study conducted for three weeks at Okayama University Japan, among tested filtered materials, charcoal substantially removed dissolved Fe form groundwater used in OLGHPS. Based on the maximum Fe retention capacity ( $3.5 \mathrm{~g} \mathrm{Fe} \mathrm{kg}^{-1}$ dry charcoal biomass), $25 \mathrm{~kg}$ dry charcoal biomass displayed adsorption of $88 \mathrm{~g}$ of dissolved Fe. Nevertheless, further field tests are required for validation of site-specific effectiveness of charcoal filter material by considering different influencing environmental factors.

\section{Conclusions}

Conclusively, among three tested filtering materials (wooden charcoal, yamazuna sand, and volcanic ash), biomaterial (charcoal) proved to be highly efficient adsorbent in terms of iron removal capacity from groundwater and in maintaining the operational matrix. Higher iron removal capacity of biomaterial can be ascribed to different functional groups, surface chemistry and surface areas available for sorption processes. Thus, charcoal-based biomaterials can be deployed as an efficient adsorbent to remove iron in OLGHPS. These low-cost and eco-friendly filter materials will be a better choice in terms of practicability and applicability, especially in resource-limited countries. Least Fe retention capacity was observed in volcanic ash. Although Fe retention capacity was also observed in yamazuna fine sand, reduction in velocity was observed due to clogging of filtering material.
Therefore, fine sand material might be suggested in those types of filters where slow velocity is required during operation. Based on the experimental results, it is plausible to calculate charcoal dry mass and can redesign the filter dimensions for real scale applications by considering the velocity, retention capacity (g Fe per kg charcoal dry mass), and filter utilization time. Application of a safety factor (about 30\%) is also suggested because the retention has higher dependency on different factors. Nevertheless, for effective designing of the filter and to estimate the retained $\mathrm{Fe}$ amount, it is highly suggested to conduct column experiments because of site-specific variations in groundwater composition and differential retention behavior under different environmental conditions.

Funding No specific funding was received for this work.

\section{Declarations}

Conflict of interest The authors declare no conflict of interest.

Open Access This article is licensed under a Creative Commons Attribution 4.0 International License, which permits use, sharing, adaptation, distribution and reproduction in any medium or format, as long as you give appropriate credit to the original author(s) and the source, provide a link to the Creative Commons licence, and indicate if changes were made. The images or other third party material in this article are included in the article's Creative Commons licence, unless indicated otherwise in a credit line to the material. If material is not included in the article's Creative Commons licence and your intended use is not permitted by statutory regulation or exceeds the permitted use, you will need to obtain permission directly from the copyright holder. To view a copy of this licence, visit http://creativecommons.org/licenses/by/4.0/.

\section{References}

Ahamad KU, Jawed M (2010) Kinetics, equilibrium and breakthrough studies for Fe (II) removal by wooden charcoal: a low-cost adsorbent. Desalination 251:137-145

Ahamad KU, Jawed M (2011) Breakthrough column studies for Iron(II) removal from water by wooden charcoal and sand: a low cost approach. Int J Enviro Res 5(1):127-138

Akhtar MS, Nakashima Y, Nishigaki M (2021) Clogging mechanisms and preventive measures in artificial recharge systems. J Groundw Sci Eng 9(3):181-201

Al-Ahmed A, Sarı A, Mazumder MAJ et al (2020) Thermal energy storage and thermal conductivity properties of OctadecanolMWCNT composite PCMs as promising organic heat storage materials. Sci Rep 10:9168

Ando T, Fujita Y, Kakinaga M et al (2017) Water purification using porous ceramics prepared by recycling volcanic ash and waste glass. Appl Water Sci 7:4109-4115

Annaduzzaman M, Rietveld LC, Ghosh D, Hoque BA, Halem D (2021) Anoxic storage to promote arsenic removal with groundwaternative iron. Water Res 202:117404

Aragaw TA, Bogale FM, Aragaw BA (2021) Iron-based nanoparticles in wastewater treatment: a review on synthesis 
methods, applications, and removal mechanisms. J Saudi Chem Soc 25(8): 101280

Awan MA, Qazi IA, Khalid I (2003) Removal of heavy metals through adsorption using sand. J Environ Sci (china) 15(3):413-416

Baveye P, Vandevivere P, Hoyle BL, DeLeo PC, de Lozada DS (1998) Environmental impact and mechanisms of the biological clogging of saturated soils and aquifer materials. Crit Rev Environ Sci Technol 28:123-191

Bouwer H (2002) Artificial recharge of groundwater: hydrogeology and engineering. Hydrogeol J 10:121-142

Camprovin P, Hernandez M, Fernandez S, Martin-Alonso J, Galofre B, Mesa J (2017) Evaluation of clogging during sand filtered surface water injection for aquifer storage and recovery (ASR): pilot experiment in the Llobregat Delta (Barcelona, Spain). Water 9:263

Contescu A, Vass M, Contescu C, Putyera K, Schwarz JA (1998) Acid buffering capacity of basic carbons revealed by their continuous pK distribution. Carbon 36:247-258

Da' ana DA, Zouari N, Ashfaq MY, Abu-Dieyeh M, Khraisheh M, Hijji YM, Al-Ghouti MA (2021) Removal of toxic elements and microbial contaminants from groundwater using low-cost treatment options. Curr Pollut Rep 7:300-324

Deliyanni EA, Kyzas GZ, Triantafyllidis KS, Matis KA (2015) Activated carbons for the removal of heavy metal ions: a systematic review of recent literature focused on lead and arsenic ions. Open Chem 13:699-708

Drijver B, Willemsen A (2001) Groundwater as a heat source for geothermal heat pumps, In: International summer school on direct application of geothermal energy, International Geothermal Association, Bad Urach, Germany, pp156-166

Ellis D, Bouchard C, Lantagne G (2000) Removal of iron and manganese from groundwater by oxidation and microfiltration. Desalination 130:255-264

Esmaeili A, Mobini M, Eslami H (2019) Removal of heavy metals from acid mine drainage by native natural clay minerals, batch and continuous studies. Appl Water Sci 9:97

Figueiredo JL, Pereira MFR (2010) The role of surface chemistry in catalysis with carbons. Catal Today 150:2-7

Garcia-Araya JF, Beltra FJ, Lvarez PA, Masa FJ (2003) Activated carbon adsorption of some phenolic compounds present in agroindustrial wastewater. Adsorption 9:107-115

Haque Su, Nasar A, Inamuddin A et al (2020) Applications of chitosan (CHI)-reduced graphene oxide (rGO)-polyaniline (PAni) conducting composite electrode for energy generation in glucose biofuel cell. Sci Rep 10:10428

Hódi M, Polyák HJ (1995) Removal of pollutants from drinking water by combined ion exchange and adsorption methods. Environ Int 21:325-331

Hoon YJ, Seong-Chun J, Jeong-Yong C et al (2017) A review on clogging mechanisms and managements in aquifer storage and recovery ASR applications. Geosci J 22:667-669

Igarashi M (2005) Saito K (2005) Estimation of impervious hydraulic gradient for used Yamasuna sand. Japanese Society of Civil Engineering (JSCE) 3:153-154

Jeong HN, Jun S-C, Cheon JY, Park M (2018) A review on clogging mechanisms and managements in aquifer storage and recovery (ASR) applications. Geosci J 22:667-669

Kalvani N, Mesdaghinia A, Yaghmaeian K, Abolli S, Saadi S, Rashidi Mehrabadi A, Alimohammadi M (2021) Evaluation of iron and manganese removal effectiveness by treatment plant modules based on water pollution index, a comprehensive approach. J Environ Health Sci Eng 19(1):1005-1013

Khatri N, Tyagi S, Rawtani D (2017) Recent strategies for the removal of iron from water: a review. J Water Process Eng 19:291-304
Kwakye-Awuah B, Sefa-Ntiri B, Von-Kiti E, Nkrumah I, Williams C (2019) Adsorptive removal of iron and manganese from groundwater. Water 11(9):1912

Kyzas GZ, Bomis G, Kosheleva RI, Efthimiadou EK, Favvas EP, Kostoglou M, Mitropoulos AC (2019) Nanobubbles effect on heavy metal ions adsorption by activated carbon. Chem Eng J 56:91-97

László K, Tombácz E, Novák C (2007) pH-dependent adsorption and desorption of phenol and aniline on basic activated carbon. Colloids Surf A Physicochem Eng Asp 306:95-101

Lim JY, Mubarak NM, Abdullah EC, Nizamuddin S, Khalid M, Inamuddin, (2018) Recent trends in the synthesis of graphene and graphene oxide-based nanomaterials for removal of heavy metals - a review. J Ind Eng Chem 66:29-34

Masciopinto C, Vurro M, Palmisano VN, Liso IS (2017) A suitable tool for sustainable groundwater management. Water Resour Manag 31:4133-4147

Mohamed EF (2011) Removal of organic compounds from water by adsorption and photocatalytic oxidation. PhD Thesis, Institut National Polytechnique de Toulouse, Toulouse, France.

Moreno JC, Gómez R, Giraldo L (2010) Removal of Mn, Fe, Ni and $\mathrm{Cu}$ Ions from wastewater using cow bone charcoal. Materials 3:452-466

Mutschmann J, Stimmelmayr F (1991) Handbook of Water Supply (in German), Franckh-Kosmos, Stuttgart, Germany

Nazir A, Zahra F, Sabri MU, Ghaffar A, Ather AQ, Khan MI, Iqbal M (2021) Charcoal prepared from Bougainvillea spectabilis leaves as low-cost adsorbent: kinetic and equilibrium studies for removal of iron from aqueous solution. Z Phys Chem 235(3):265-279

Nazir H, Batool M, Osorio FJB, Isaza-Ruiz M, Xu X, Vignarooban K, Phelan P, Inamuddin KAM (2019) Recent developments in phase change materials for energy storage applications: a review. Int J Heat Mass Transf 129:491-523

Oba N, Tsuyuki T, Ebihara H (1967) Mineral and chemical composition, and genesis of the Shirasu (I) (in Japanese). J Japan Assoc Min Petr Econ Geol 58(3):81-97

Olivera S, Chaitra K, Venkatesh K et al (2018) Cerium dioxide and composites for the removal of toxic metal ions. Environ Chem Lett 16:1233-1246

Pacini VA, María IA, Sanguinetti G (2005) Removal of iron and manganese using biological roughing up flow filtration technology. Water Res 39:4463-4475

Parimalarenganayaki S (2021) Managed aquifer recharge in the gulf countries: a review and selection criteria. Arab J Sci Eng 46:1-15

Radovic LR (1999) Surface chemistry of activated carbon materials: state of the art and implications for adsorption. In: Schwarz JA, Contescu CI (eds) Surfaces of nanoparticles and porous materials. Marcel Dekker, NewYork, pp 529-565

Rafferty K (2003) Ground water issues in geothermal heat pump systems. Ground Water 41:408-410

Ruemenapp R, Hartwig C, Akhtar MS, Nishigaki M (2013) Porous media filter test in order to prevent well clogging during groundwater reinjection due to ferrous and ferric mineral precipitation. In: Martin R (ed) clogging issues associated with managed aquifer recharge methods, IAH commission on managing aquifer recharge, Australia, pp 50-64

Ryan J, Estefan G, Rashid A (2001) Soil and Plant Analysis Laboratory Manual, 2nd Ed., Aleppo, Syria.

Sendja BT, Castillo NAM, Portales LR, Kouonang ST, Delgado GJL, Álvarez CC, Olivi L (2021) Iron adsorption in Cameroon volcanic ashes insights from x-ray absorption spectroscopy. Physica B Condens Matter 617:413128

Seppánen HT (1992) Experiences of biological iron and manganese removal in Finland. Water Environ J 6:333-340 
Shen J, Ni R (2017) Experimental investigation of clogging dynamics in homogeneous porous medium. Water Resour Res 53:1879-1890

Siabi WK, Owusu-Ansah ED-J, Essandoh HMK, Asiedu NY (2021) Modelling the adsorption of iron and manganese by activated carbon from teak and shea charcoal for continuous low flow. WaterEnergy Nexus 4:88-94

Simeonidis K, Mitrakas M (2021) Technologies developing in heavy metals' removal from water. Water 13:860

Stumm W, Morgan JJ (1996) Aquatic chemistry: chemical equilibria and rates in natural waters. Wiley-Interscience, New York

Sun C, Wang G, Sun C, Liu R, Zhang Z, Marhaba T, Zhang W (2021) Optimization of iron removal in water by nanobubbles using response surface methodology. Water Supply 21(4):1608-1617

Syed Ibrahim GP, Isloor AM, Inamuddin AAM, Ismail AF, Kumar R, Ahamed MI (2018) Performance intensification of the polysulfone ultrafiltration membrane by blending with copolymer encompassing novel derivative of poly(styrene-co-maleic anhydride) for heavy metal removal from wastewater. Chem Eng J 353:425-435

Tang X, Zhu X, Huang K, Wang J, Guo Y, Xie B, Li G, Liang H (2021) Can ultrafiltration singly treat the iron- and manganese-containing groundwater? J Hazard Mater 409:124983

Teunissen K (2007) Iron removal at groundwater pumping station. MSc Thesis, Faculty of Civil Engineering and Geosciences, Department of Water Management Sanitary Engineering Section Delft, Netherlands.

Toscano G, Caristi C, Cimino G (2008) Sorption of heavy metal from aqueous solution by volcanic ash. C R Chim 11(6-7):765-771
Vries D, Bertelkamp C, Kegel FS, Hofs B, Dusseldorp J, Bruins JH, de Vet W, van den Akker B (2017) Iron and manganese removal: recent advances in modelling treatment efficiency by rapid sand filtration. Water Res 109:35-45

Worch E (2012) Adsorption Technology in Water Treatment, De GruyDe Gruyter, Berlin/Boston.

Wotton R (2002) Water purification using sand. Hydrobiologia 469:193-201

Ye X, Cui R, Du X, Ma S, Zhao J, Lu Y, Wan Y (2019) Mechanism of suspended kaolinite particle clogging in porous media during managed aquifer recharge. Groundwater 57(5):764-771

Zhao W, Wang W, Liu S, Qu S, Sun X, Meng Y (2021) Water distribution and silt clogging in the strong-seepage zone infiltration process of yufuhe river from yellow river water based on the twodimensional sand tank model. Water 13:1200

Zheng Q, Wang W, Liu S et al (2020) Physical clogging experiment of sand gravel infiltration with yellow river water in the Yufuhe river channel of Jinan, China. Front Earth Sci 14:306-314

Zhou NQ, Zhao S, Song W, Otani J (2014) Contaminant migration in unsaturated porous media using X-ray computerized tomography (CT). Water Sci Technol 69(5):953-959

Publisher's Note Springer Nature remains neutral with regard to jurisdictional claims in published maps and institutional affiliations. 